\title{
Relationship Between Within-Visit Blood Pressure Variability and Kidney Function in Patients with Arterial Hypertension
}

\author{
Andrey Y. Kravchenko, PhD, ScD; Anna A. Chernykh; \\ Andrey V. Budnevsky, PhD, ScD; Evgeniy S. Ovsyannikov, PhD*; \\ Alexey V. Chernov, PhD, ScD; Anna A. Feskova \\ Voronezh State Medical University named after N.N. Burdenko \\ Voronezh, The Russian Federation
}

\begin{abstract}
The main purpose of this study was to investigate the features of within-visit blood pressure variability (BPV) in patients with arterial hypertension $(\mathrm{AH})$ and to assess the relationship of those features to impaired renal filtration.

Material and Methods: The study included 120 patients with AH Stages I and II (ESH/ESC, 2013): 58(48.3\%) men and $62(51.7 \%$ ) women aged from 22 to 73 years (mean age $58.7 \pm 15$ years). Average duration of AH was $15.0 \pm 6.7$ years. BP was measured three times at 2-minute intervals during one visit. Within-visit BPV was evaluated by the presence of an absolute difference (AD) between any two readings of three SBP measurements of more than $5 \mathrm{mmHg}$. All patients underwent a comprehensive examination, which included blood and urine tests, kidney ultrasound, assessment of blood levels of creatinine and TnT, and calculation of GFR.

Results: Depending on the response of BP to repeated measurements, three types of BPV were identified. A prognostically unfavorable type of BPV, which is characterized by SBP-AD $>5 \mathrm{mmHg}$ between the third and first measurements, was identified. Patients of this group had the lowest eGFR value that indicates more pronounced renal damage, and, as a consequence, worse prognosis. Also in these patients, there was an increase in TnT level, which is a predictor of the development of adverse cardiovascular complications. (International Journal of Biomedicine. 2017;7(2):91-95.)
\end{abstract}

Key Words: arterial hypertension •blood pressure variability • glomerular filtration rate • chronic kidney disease

\section{Abbreviations}

AH, arterial hypertension; BP, blood pressure; BPV, BP variability; CKD, chronic kidney disease; Cr, creatinine; GFR, glomerular filtration rate; eGFR, estimated GFR; SBP, systolic BP; SBP-AD, absolute difference in SBP; TnT, troponin T.

\section{Introduction}

$\mathrm{AH}$ is an important global health challenge because of its high prevalence and resulting cardiovascular disease and CKD. (1) Epidemiological studies have shown that in Russia $\mathrm{AH}$ is observed in $40.8 \%$ of the adult population (more than 42 million people). ${ }^{(2)}$ In recent years, researchers have found

*Corresponding author: Evgeniy S. Ovsyannikov, PhD. Department of faculty therapy, Voronezh State Medical University n.a. N.N. Burdenko.Voronezh, Russia.E-mail: ovses@yandex.ru. that cardiovascular (CV) complications of hypertension depend not only on the absolute values of BP, but also on the degree of $\mathrm{BPV}^{(3,4)}$ Short-term BPV within a 24-hour period is increasingly recognized as both a marker and a risk factor for cardiovascular disease. ${ }^{(5-9)}$ However, few studies have examined the importance of BPV measured during a single clinic visit (i.e., very-shortterm BPV). Recent studies have demonstrated that within-visit BPV is associated with target organ damage (left ventricular hypertrophy and albuminuria). ${ }^{(10)}$

CKD, since the earliest stages, has been associated with a high risk of premature $\mathrm{CV}$ events. ${ }^{(11-13)}$ Only a few studies have 
explored the relationship between short-term BPV/withinvisit BPV and markers of early renal damage, with conflicting results. ${ }^{(10,14-19)}$ It could be hypothesized that an enhanced withinvisit BPV in patients with early renal abnormalities may help to explain in part their increased $\mathrm{CV}$ risk.

Currently, the most sensitive indicator of myocardial damage is the blood level of troponin. The troponin complex consists of three subunits: troponin $\mathrm{T}$ (tropomyosin binding), troponin I (inhibitory), and troponin $\mathrm{C}$ (calcium binding). $\mathrm{TnT}$ has the highest specificity for myocardial damage. ${ }^{(20)}$ In several studies, it was noted that a stable increase in TnT level is often observed among patients with decreased renal function. Reduced renal clearance is probably not the primary mechanism of persistently elevated troponin levels in patients with $\mathrm{CKD}$, although this issue is controversial. ${ }^{(21-24)}$ Elevated troponin levels in patients with CKD may be explained by cardiac injury associated with chronic structural heart disease (such as coronary artery disease or heart failure) rather than acute ischemia, especially when levels do not change rapidly over time. ${ }^{(25)}$ A recent study showed that an increased TnT level is associated with an increase in signs of heart failure. ${ }^{(26)}$ In this case, even a slight increase in TnT level can be considered a negative sign in predicting adverse $\mathrm{CV}$ complications at the subclinical level.

The main purpose of this study was to investigate the features of within-visit BPV in AH patients and to assess the relationship of those features to impaired renal filtration.

\section{Materials and methods}

The study included 120 patients with AH Stages I and II. (ESH/ESC, 2013) ${ }^{(4)}$ : 58(48.3\%) men and 62(51.7\%) women aged from 22 to 73 years (mean age $58.7 \pm 15$ years). $20(16.67 \%)$ people were cigarette smokers. Average duration of AH was $15.0 \pm 6.7$ years. Type 2 diabetes was identified in $32(26.67 \%)$ patients. $58(48.34 \%)$ patients had myocardial infarction in anamnesis.

The diagnosis of AH was based on 2013 ESH/ESC Guidelines for the management of AH. ${ }^{(13)}$ All patients were checked on office BP using Korotkov's method after a 5-min rest in the seated position with back support. BP was measured three times on the left arm at 2-minute intervals with the use of a validated semi-automated electronic device (UA-787). All measurements were carried out on the same time between 9:00 and 10:00. All patients underwent a comprehensive examination, which included blood and urine tests, kidney ultrasound, and assessment of blood levels of creatinine $(\mathrm{Cr})$ and TnT. Blood samples were collected within 4-48 hours after admission.

Determination of serum TnT was performed on the Elecsys-2010 automatic analyzer Roche Diagnostics GmbH, Germany) using Elecsys Troponin T Stat Assay. The limit of detection (LOD) for this assay is $0.01 \mathrm{ng} / \mathrm{ml}$. A cut-off of 0.1 $\mathrm{ng} / \mathrm{ml}$ was used in assessing the prognostic significance of TnT.

GFR was estimated using the CKD-EPI (eGFR(CKDEPI)) equation according to the recommendations of the National Kidney Foundation. ${ }^{(27,28)}$ The CKD-EPI equation reclassifies people at lower risk of CKD and death into higher
eGFR categories, suggesting more accurate categorization. (29)

The study was approved by the local ethics committee. Written informed consent was obtained from each patient. Statistical processing of data was carried out using the program SPSS 10.0 software. Correlation analysis was carried out using the non-parametric Spearmen criterion. A probability value of $\mathrm{P}<0.05$ was considered statistically significant.

\section{Results and Discussion}

Within-visit BPV was evaluated by the presence of an absolute difference (AD) between any two readings of three SBP measurements of more than $5 \mathrm{mmHg}$. According to this criterion, we have identified several options for BPV. In $37(30.84 \%)$ patients, there was a systematic increase in BP by more than $5 \mathrm{mmHg}$ in successive measurement (Response A). Reduction of BP during repeated measurements $>5 \mathrm{mmHg}$ was noted in 23(19.17\%) patients (Response B). No difference $>5$ $\mathrm{mmHg}$ between the measurements was observed in 24(20\%) patients (Response C). In 36(30\%) patients, multidirectional BP fluctuations were noted between the measurements (Response D) (Fig.1).

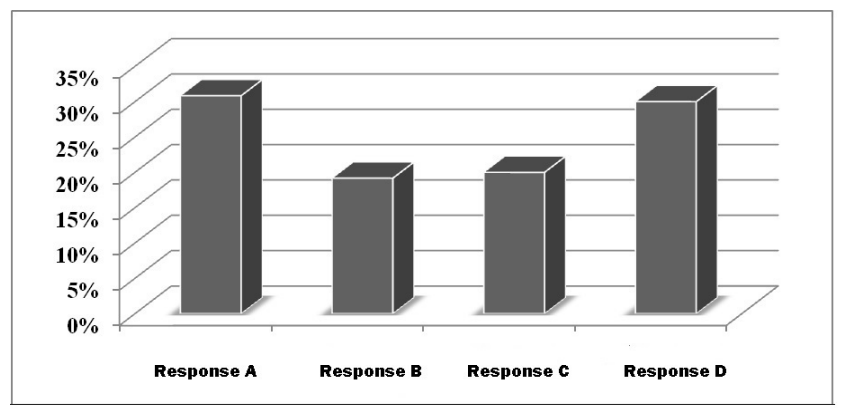

Fig. 1. Frequency of the different BP responses during repeated measurements.

Depending on the response of $\mathrm{BP}$ to repeated measurements, we identified three types of BPV. Type 1: SBP$\mathrm{AD}$ is $>5 \mathrm{mmHg}$ between the third and the first measurements; Type 2: SBP-AD is $>5 \mathrm{mmHg}$ between the first and the third measurements. Type 3: SBP-AD is $<5 \mathrm{mmHg}$ during repeated measurements. Analysis of BPV types allowed us to better analyze the body's response to repeated measurements and to evaluate the relationship with other indicators.

Different authors distinguished several types of shortterm BPV; $;^{(3,30,31)}$ however, we have not previously encountered in the literature an approach such as ours to the evaluation of the types of BP response to repeated measurements, which indicates the relevance and insufficient knowledge of this problem.

After GFR calculation, we determined CKD stages in our patients. Most frequent $(46.7 \%)$ was Stage 2, next was Stage 3A $(22.5 \%)$, then 3B (20\%), Stage $1(10 \%)$, and finally Stage 4 (0.83\%) (Fig.2).

We also analyzed the distribution of CKD stages depending on the BPV type (Fig.3). CKD Stages 3A and 3B were more often observed in patients with BPV Type 1 ( $25 \%$ 
and $33.34 \%$ of cases, respectively). Stage 2 had almost the same frequency distribution by BPV type. Stage 1 did not exceed 5 cases in each type; Stage 4 was registered in one patient with BPV Type 1.

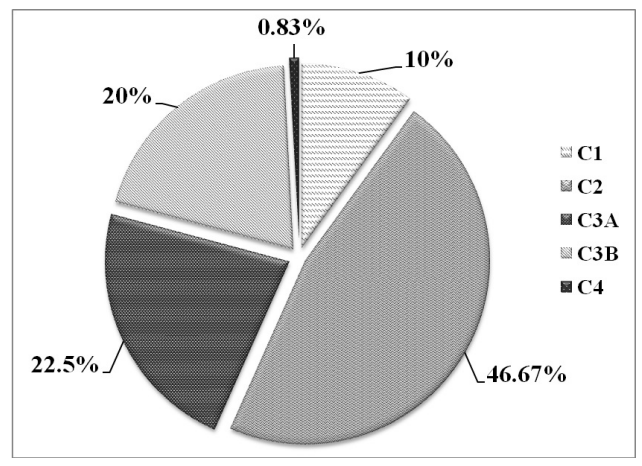

Fig. 2. CKD stages in studied patients.



Fig. 3. Distribution of CKD stages depending on the BPV type

To establish the relationship between BPV and a number of parameters, we conducted a correlation analysis (Table 1). According to the data obtained, the greatest prognostic value belonged to BPV Type 1. This type was associated with decreased eGFR - up to Stage 3B.

Table 1.

Correlations between BPV types and clinical characteristics of patients.

\begin{tabular}{|c|c|c|c|c|c|c|c|}
\hline $\begin{array}{c}\text { BPV } \\
\text { Type }\end{array}$ & Gender & Age & BMI & Cr & eGFR & Diabetes & TnT \\
\hline 1 & $\begin{array}{c}-0.015 \\
\mathrm{P}=0.12\end{array}$ & $\begin{array}{c}-0.09 \\
\mathrm{P}=0.21\end{array}$ & $\begin{array}{c}\mathrm{P}=0.36 \\
\mathrm{P}=0.62\end{array}$ & $\begin{array}{c}-0.58 \\
\mathrm{P}=0.001\end{array}$ & $\begin{array}{c}\mathrm{P}=0.001 \\
\mathrm{P}=0.27\end{array}$ & $\begin{array}{c}0.48 \\
\mathrm{P}=0.0021\end{array}$ \\
\hline 2 & -0.019 & -0.078 & 0.096 & 0.22 & -0.19 & -0.23 & 0.21 \\
& $\mathrm{P}=0.21$ & $\mathrm{P}=0.31$ & $\mathrm{P}=0.27$ & $\mathrm{P}=0.012$ & $\mathrm{P}=0.021$ & $\mathrm{P}=0.17$ & $\mathrm{P}=0.07$ \\
\hline 3 & $\begin{array}{c}-0.024 \\
\mathrm{P}=0.28\end{array}$ & $\begin{array}{c}\mathrm{P}=0.1 \\
0.16\end{array}$ & $\begin{array}{c}\mathrm{P}=0.11 \\
\mathrm{P}=0.025\end{array}$ & $\begin{array}{c}\mathrm{P}=0.14 \\
-0.023\end{array}$ & $\begin{array}{c}\mathrm{P}=0.24 \\
\mathrm{P}=0.15\end{array}$ \\
\hline
\end{tabular}

In the literature, there are few reports on the connection between the decrease in eGFR and BPV. One opinion is that this phenomenon can be associated with dysfunction of the endothelium. ${ }^{(32)}$ As GFR decreases, the blood accumulates the inflammatory cytokines, lipid peroxidation products, and other vasoactive metabolites. ${ }^{(33,34)}$ According to M. Zwolinska, in this condition, the synthesis of VCAM-1 is enhanced, triggering several reactions that cause endothelial dysfunction. ${ }^{(35)}$

When measuring serum TnT, we found that in patients with BPV Type 1, TnT level ranged between $0.1 \mathrm{ng} / \mathrm{ml}$ and $0.3 \mathrm{ng} / \mathrm{ml}(0.23 \pm 0.12 \mathrm{ng} / \mathrm{ml})$, whereas in patients with other types of BPV, TnT level did not exceed the upper reference limit. This fact indicates a more significant lesion of the myocardium as a target organ in AH patients with BPV Type 1 , which is associated with an unfavorable cardiovascular prognosis. During analysis, we found correlations between the increase in SBP during the first and third measurements, a decrease in eGFR, and an increase in TnT level in AH patients.

\section{Conclusion}

Thus, our results show that within-visit BPV may be one of the important criteria for assessing cardiovascular complications in hypertension. We have identified a prognostically unfavorable type of $\mathrm{BPV}$, which is characterized by SBP-AD $>5 \mathrm{mmHg}$ between the third and first measurements. Patients of this group had the lowest eGFR value that indicates more pronounced renal damage, and, as a consequence, worse prognosis. Also in these patients, there was an increase in TnT level, which is a predictor of the development of adverse cardiovascular complications.

\section{Competing interests}

The authors declare that they have no competing interests.

\section{References}

1. Mills KT, Bundy JD, Kelly TN, Reed JE, Kearney PM, Reynolds K, Chen J, He J. Global Disparities of Hypertension Prevalence and Control: A Systematic Analysis of PopulationBased StudiesFrom90Countries.Circulation.2016;134(6):44150. doi: 10.1161/CIRCULATIONAHA.115.018912.

2. The Demographic Yearbook of Russia. Statistical handbook. Rosstat. - M., 2015. [in Russian].

3. Kravchenko AYa, Chernykh AA, Budnevsky AV. [Variability of arterial pressure and renal function]. Klin Med (Mosk). 2016; 94(4):245-9. [Article in Russian].

4. Kravchenko AYa, Chernykh AA, Budnevsky AV. [Variability of arterial pressure in patients with arterial hypertension and overweight]. Cardiovascular Therapy and Prevention (Mosk). 2016;15(S):100. [Article in Russian].

5. Schillaci G, Bilo G, Pucci G, Laurent S, MacquinMavier I, Boutouyrie P,et al. Relationship between short-term blood pressure variability and large-artery stiffness in human hypertension: findings from 2 large databases. Hypertension. 2012;60(2):369-77. doi: 10.1161/ HYPERTENSIONAHA.112.197491.

6. Pringle E, Phillips C, Thijs L, Davidson C, Staessen JA, 
de Leeuw PW, et al.; Syst-Eur investigators. Systolic blood pressure variability as a risk factor for stroke and cardiovascular mortality in the elderly hypertensive population. J Hypertens. 2003,21(12):2251-7.

7. Sega R, Corrao G, Bombelli M, Beltrame L, Facchetti $\mathrm{R}$, Grassi $\mathrm{G}$, et al. Blood pressure variability and organ damage in a general population: results from the PAMELA Study (Pressioni Arteriose Monitorate e Loro Associazioni). Hypertension. 2002;39(2 Pt 2):710-4.

8. Hansen TW, Thijs L, Li Y, Boggia J, Kikuya M, BjörklundBodegård K, et al.; International Database on Ambulatory Blood Pressure in Relation to Cardiovascular Outcomes Investigators. Prognostic value of reading-to-reading blood pressure variability over 24 hours in 8938 subjects from 11 populations. Hypertension. 2010;55(4):1049-57. doi: 10.1161/HYPERTENSIONAHA.109.140798.

9. Kikuya M, Hozawa A, Ohokubo T, Tsuji I, Michimata M, Matsubara M, et al. Prognostic significance of blood pressure and heart rate varisbilities: the Ohasama Study. Hypertension. 2000; 36(5):901-6.

10. Wei FF, Li Y, Zhang L, Xu TY, Ding FH, Wang JG, Staessen JA. Beat-to-beat, reading-to-reading, and day-today blood pressure variability in relation to organ damage in untreated Chinese. Hypertension. 2014;63(4):790-6. doi: 10.1161/HYPERTENSIONAHA.113.02681.

11. Gansevoort RT, Correa-Rotter R, Hemmelgarn BR, Jafar TH, Heerspink HJ, Mann JF, et al. Chronic kidney disease and cardiovascular risk: epidemiology, mechanisms, and prevention. Lancet. 2013;382(9889):339-52. doi: 10.1016/ S0140-6736(13)60595-4.

12. Cerasola G, Cottone S, Mulè G. The progressive pathway of microalbuminuria: from early marker of renal damage to strong cardiovascular risk predictor. J Hypertens. 2010;28(12):2357-69. doi: 10.1097/HJH.0b013e32833ec377. 13. Mancia G, Fagard R, Narkiewicz K, Redon J, Zanchetti A, Böhm M, et al. $2013 \mathrm{ESH} / \mathrm{ESC}$ guidelines for the management of arterial hypertension: the Task Force for the Management of Arterial Hypertension of the European Society of Hypertension (ESH) and of the European Society of Cardiology (ESC). Eur Heart J. 2013;34(28):2159-219. doi: 10.1093/eurheartj/eht151 14. Li Y, Liu J, Wang W, Zhao D.The association between within-visit blood pressure variability and carotid artery atherosclerosis in general population. PLoS One. 2014;9(5):e97760. doi: 10.1371/journal.pone.0097760.

15. Tatasciore A1, Renda G, Zimarino M, Soccio M, Bilo G, Parati G, et al. Awake systolic blood pressure variability correlates with target-organ damage in hypertensive subjects. Hypertension. 2007;50(2):325-32.

16. Manios E, Tsagalis G, Tsivgoulis G, Barlas G, Koroboki $\mathrm{E}$, Michas F, et al. Time rate of blood pressure variation is associated with impaired renal function in hypertensive patients. J Hypertens. 2009;27(11):2244-8. doi: 10.1097/ HJH.0b013e328330a94f.

17. Okada H, Fukui M, Tanaka M, Inada S, Mineoka Y, Nakanishi $\mathrm{N}$, et al. Visit-to-visit variability in systolic blood pressure is correlated with diabetic nephropathy and atherosclerosis in patients with type 2 diabetes. Atherosclerosis. 2012; 220(1):155-9. doi: 10.1016/j. atherosclerosis.2011.10.033.

18. Shin JH, Shin J, Kim BK, Lim Y-H, Park H-C, Choi SI, et al. Within-visit blood pressure variability: relevant factors in the general population. J Hum Hypertens. 2013;27 (5):32834. doi: 10.1038/jhh.2012.39.
19. Rahman M, Pressel S, Davis BR, Nwachuku C, Wright Jr JT, Whelton PK et al; ALLHAT Collaborative Research Group. Cardiovascular outcomes in high-risk hypertensive patients stratified by baseline glomerular filtration rate. Ann Intern Med. 2006;144(3):172-80.

20. Xu RY, Zhu XF, Yang Y, Ye P. High-sensitive cardiac troponin T. J Geriatr Cardiol. 2013;10(1):102-9. doi: 10.3969/j.issn.1671-5411.2013.01.015.

21. Stacy SR, Suarez-Cuervo C, Berger Z, Wilson LM, Yeh HC, Bass EB, Michos ED. Role of troponin in patients with chronic kidney disease and suspected acute coronary syndrome: a systematic review. Ann Intern Med. 2014;161(7):502-12. doi: 10.7326/M14-0746.

22. Newby LK, Jesse RL, Babb JD, Christenson RH, De Fer TM, Diamond GA, et al. ACCF 2012 expert consensus document on practical clinical considerations in the interpretation of troponin elevations: a report of the American College of Cardiology Foundation Task Force on Clinical Expert Consensus Documents. J Am Coll Cardiol 2012; 60(23):2427-63. doi: 10.1016/j.jacc.2012.08.969.

23. Hasegawa M, Ishii J, Kitagawa F, Kanayama K, Takahashi $\mathrm{H}$, Ozaki Y, et al. Prognostic value of highly sensitive troponin $\mathrm{T}$ on cardiac events in patients with chronic kidney disease not on dialysis. Heart Vessels. 2013;28(4):473-9. doi: 10.1007/ s00380-012-0273-2.

24. Bjurman C, Petzold M, Venge P, Farbemo J, Fu ML, Hammarsten O. High-sensitive cardiac troponin, NTproBNP, hFABP and copeptin levels in relation to glomerular filtration rates and a medical record of cardiovascular disease. Clin Biochem. 2015;48(4-5):302-7. doi: 10.1016/j. clinbiochem.2015.01.008.

25. Jaffe AS Chasing troponin: how low can you go if you can see the rise? [Editorial]. J Am Coll Cardiol 2006;48(9):1763-4 26. Seliger SL, Hong SN, Christenson RH, Kronmal R, Daniels LB, Lima JAC, et al. High Sensitive Cardiac Troponin $\mathrm{T}$ as an Early Biochemical Signature for Clinical and Subclinical Heart Failure: MESA (Multi-Ethnic Study of Atherosclerosis). Circulation. 2017;135(16):1494-1505. doi: 10.1161/CIRCULATIONAHA.116.025505.

27. KDIGO 2012 Clinical Practice Guideline for the Evaluation and Management of Chronic Kidney Disease. Kidney Int (Suppl.) 2013; 3:1-150.

28. Smirnov AV, Schilov EM, Dobronravov VA, Kayukov IG, Bobkova IN, Shcveczov MU, etal. [National recommendations. National recommendations. Chronic illness of kidneys: main principles of screening, diagnostics, preventive maintenance and approaches to treatment]. Klinicheskaja nefrologija. 2012;4:4-26. [in Russian].

29. Stevens LA, Li S, Kurella Tamura M, Chen SC, Vassalotti JA, Norris KC, et al. Comparison of the CKD Epidemiology Collaboration (CKD-EPI) and Modification of Diet in Renal Disease (MDRD) study equations: risk factors for and complications of CKD and mortality in the Kidney Early Evaluation Program (KEEP). Am J Kidney Dis. 2011;57(3 Suppl 2):S9-16. doi: 10.1053/j.ajkd.2010.11.007.

30. Gorbunov VM. [Modern ideas about the variability of blood pressure]. Racional'naja farmakoterapija $\mathrm{v}$ kardiologii. 2012;8:810-818. [Article in Russian].

31. Okada R, Yasuda Y, Tsushita K, Wakai K, Hamajima N, Matsuo S.Within-visit blood pressure variability is associated with prediabetes and diabetes. Sci Rep. 2015;5:7964. doi: 10.1038/srep07964.

32. Panina IY, Petrishchev NN, Smirnov AV, Rumyantsev 
ASh, Degtereva OA. [Arterial hypertension and endothelial dysfunction in chronic kidney disease[. Arterial'naia gipertenziia. 2006;4:352-7. [Article in Russian].

33. Smirnov AB, Dobronravov VA, Kaiukov IG. [CardioRenal Continuum: Pathogenetic Basics of Preventive Nephrology]. Nephrology (Saint-Petersburg). 2005; 9(3):712. [Article in Russian].
34. Amann K, Gross ML, Ritz E. Pathophysiology underlying accelerated atherogenesis in renal disease: closing in on the target. J Am Soc Nephrol. 2004;15(6):1664-6.

35. Musial K, Zwolinska D, Polak-Jonkisz D, Berny U, Szprynger K, Szczepanska M. Serum VCAM-1, ICAM-1, and L-selectin levels in children and young adults with chronic renal failure. Pediatr Nephrol. 2005; 20(1):52-5. 